\title{
New Universalism: Categorization of Terms and Paradigm of Approaches
}

\author{
L. Zakharova \\ Tyumen State Institute of Culture \\ Tyumen, Russia \\ O. Lazareva \\ University of Tyumen \\ Tyumen, Russia \\ opl-tyumen@mail.ru
}

\author{
T. Kononova \\ Tyumen State Institute of Culture \\ Tyumen, Russia \\ E. Akulich \\ Tyumen State Institute of Culture \\ Tyumen, Russia
}

\author{
O. Goreva \\ Industrial University of Tyumen \\ Tyumen, Russia
}

\begin{abstract}
The purpose of the research is to analyze universals from the paradigmatic and interdisciplinary points of view. The authors give their own concept of universalism, based on the epistemological approach and backed by history, philosophy, and cultural studies. Undoubtedly, universals reflect an image of a person of a historically definite type of culture. They represent a person's place in the world, social relations and spiritual life. These parameters are changeable, but at the same time they can be permanent. The article shows the categorization of the concept of universalism and underlines the variety of its use. Universals are not the same in different cultures, but they are classified on the similar basis. The authors name this principle of classification a general denominator of cultures, which includes ideology, values, symbols, and meanings. Universals vary in their content, but have the same form in various cultures. The authors of the article argue that the border between "universals of culture" and "universals of civilization" is unstable and determined by a situation. The article proves the thesis that the system of universals is not closed. Due to the development and the processes of person's adaptation to the reality, some universals disappear; others emerge. The authors believe that there are also eternal, permanent universals, which express the main needs of a person.
\end{abstract}

Keywords - universalism, universals, paradigm, culture, approach

\section{INTRODUCTION}

The concept "universals" is used to analyze both ideal and real cultural phenomena. This term is also used to describe modern globalization processes and it is understood in the context of "universal - local". We often consider the terms "categories of culture" and "universals of culture" to be synonyms. We can also speak about a new ideological aspect of the term. Many scientists think that universals reflect the image of a person characteristic to a historically certain type of culture and an idea of his place in the world, social relations and spiritual life. Ideological universals determine the way a person interprets, understands and experiences the world. The concepts "categories of culture", "universals of culture", "ideological universals" are often used as identical and interchangeable.

T. Oizerman explained the change in the concept in the following way: "The idea of universals in the cultural sphere implies a nontrivial approach to the traditional problem. This cannot be implemented by extrapolation of the concept of universals to cultural phenomena. These phenomena are not general, but specific concepts and categories forming culture" [1].

Taking into consideration new aspects of the use of the concept, V. Stepin suggests that "we should distinguish different historic attempts to make culture universal and introduce the concept of "new universalism" to characterize the current mechanism of cultural interaction" [2].

In the middle of the $20^{\text {th }}$ century anthropologists indicated the importance of appealing to general concepts of culture. They analyzed a number of local cultures that had similar features designated as universals. The number of universals increases as human needs and the ways of their satisfaction becomes complex, and new activities appear.

\section{PROBLEM STATEMENT}

Researchers in different spheres have been trying to find the universal foundation of the reality surrounding a human being for a long time. They turned to religion and philosophy, natural sciences and humanities as the main sources of the universal. The word "universals" originates from a Latin word "Universalis", which means "common". In medieval philosophy, this word defined the concept of the general features of things. In linguistics, this is the concept of forms inherent to most languages. This term is used in mathematics and other sciences. In philosophy, the word "universals" has a long history of use. Since the time of Plato, the problem of universals has touched upon such issues as the foundations of the real existence, the way in which the ideal exists, the 
correlation of thought and reality, as well as the connection of the individual, the special and the general. In the twentieth century, they began to use the term in a socio-cultural context to denote the qualities inherent to the cultures of all nations, regardless of geography, history and other differences.

Having discovered the similarity of universals in each culture under study, the scientists came to the conclusion that universals were not similar in content. That was the classification on a general basis. The principle of classifying the universals of culture on a general basis is the "general denominator of cultures". What can we consider to be the general denominator of cultures, or what principles of the classification exist at the present time? This is the question we are going to answer in our article.

\section{MATERIALS AND METHODS}

There are a few approaches to the problem.

First, we can speak about the anthropological approach. The researchers study a person with his daily needs. American anthropologist George Peter Murdoch made a great contribution to the study of cultural universals. He was the first to formulate the concept of a universal cultural model and the evolution of kinship systems. Murdoch described 60 universals of culture: making tools, joint labor; sport; education; rituals; kinship systems; rules gender interaction; language and others. Murdoch's compatriot C. Kluckhohn believed that the basis of cultural universals are biological needs (genders, babies' helplessness, their need for care and education, the need for food, warmth and sex, age differences between people, etc.) [3]. Another anthropologist Clark Wissler distinguished the following universals: speech (language), art, mythology and scientific knowledge, religious practice, family and social system, property, government, war. He called them universal patterns (structures, patterns) of any culture [4].

The second approach to the study of universals is the philosophical-anthropological approach. Human existence is understood as three main attitudes of a man to the world: attitude to the nature and artificially created environment, where he lives; attitude to other people and social groups; attitude to the ideal world in which a man accumulates his own experience and the social experience of generations. These attitudes make it possible to classify cultural universals.

The third approach to the problem of universals is a sociological approach. A good example of this approach is T. Parsons" concept of "evolutionary universals". The author believed that universals were caused by social processes in the course of the development and complication of the societies, regardless of their cultural features and the diversity of external conditions. Four of these evolutionary universals exist in all known societies: the communication system; kinship system; a certain form of religion; technology. The degree of development of evolutionary universals indicates the level of the adaptive capability of the society. "Among the processes of change, the most important for the evolutionary perspective are the processes that enhance the adaptive capability either within the society through generation of a new type of structure, or through cultural penetration and the involvement of other factors together with a new type of structure, within other societies and, possibly, in later periods" [5].

The fourth approach is philosophical-cultural. This approach distinguishes a few classifications of universals. A. Kravchenko, for example, suggests a division of universals into universal inherent in the whole human race, general inherent in a number of societies and peoples, and unique or specific [6]. Classification of cultures on the basis of the interaction between something common, something particular and something unique is efficient.

Another classification of universals is based on the traditional philosophical relationship between the material and the ideal. The main criterion of distinguishing universals is their belonging to either material or ideal side of the culture, in other words, we should take into account the quality of their objectivity or subjectivity [7].

Some researchers distinguish between the notions of "universals of culture" and "universals of civilization'. This division is based on the scientific view on the relationship between civilization and culture. According to O. Spengler, civilization is the terminal of cultural development, its outcome. K. Isupov believes that the universals of civilization is "a circle of concepts defining the results of technological activity, its products of the second half of the 19th century that were perceived as the negative of the culture" [8].

Unlike cultural universals, universals of civilization are characterized by a pseudo-existential feature, and they do not signify the quality of historical life, they only signify the quantity of progress.

Some cultural scientists classify universals according to their vision of culture and its definition. "These basic properties of the cultural science are distinguished and described using special concepts and categories. The categories of "chronotope" (space-time), "culture hero", "language integrator of the culture" and some others are the main ones" [9]. Why does M. Naidorf distinguish these universals? The answer is simple. The author proves that these universals form the foundation of any culture and they are closely connected. We agree that these universals are essential. However, other, equally important universals can be distinguished.

There is a possibility of a situation that is described in the famous parable about the blind, touching different parts of the elephant and giving different descriptions of the animal. In this regard, we can also remember the biblical parable about the Tower of Babel. Thus, we can point out that the problem of the unity of culture is a language problem, one of its old and fundamental problems. At the same time, it is possible to conduct "a comparative study of cultures in different forms and their development in the course of the world history and in the space of five continents if we find the" signs of their comparability" [9]. An attempt to link the definition of culture with cultural universals is constructive in this study.

The problem of determining the universals of culture, their comparability is related to the fact that the search for the classification of the universals of culture goes in parallel with finding the generally accepted definition of culture. 
Sometimes these searches do not complement each other, which give rise to contradictions between the content of universals and the forms of real life and functioning of the culture.

A lot of existing definitions of culture (1000) cannot contribute to the generally accepted distinguishing of its universals. Y. Larin writes about this: "The whole diversity of existing ... approaches can be reduced to four main concepts: substantive, normative, axiological and symbolic. They compete and sometimes sharply oppose each other in assessing their heuristic capabilities" [10]. "At the same time, in different historical periods a different concept acts as culture constituent or backbone element".

In recent years, we have observed the appearance of the concepts of culture that are aimed at synthesizing these approaches to culture definition. The attempt of synthesis belongs to a well-known Russian Philosopher V. Sagatovsky. He recorded two general, opposite to each other, approaches to understanding culture: The first approach contains a question: "... is culture an attribute of any manifestation of human existence, or does it characterize only its positive side, being the opposite of anti-culture?" [11]. V. Sagatovsky calls the second approach "ideological". In his opinion, it reflects a culture from the standpoint of its ideals. This approach takes culture for granted. According to it, anti-culture is opposed to culture. F. Selivanov wrote, "Culture is the perfection, the best thing in comparison with what it was, it is bright and kind, it is warmth in life, it is the creation of values... The lack of culture, anti-culture opposes to culture..." [12].

In the broadest sense, culture is also opposed to nature as artificial to natural, not created by man. The categorical image of culture reflects it as one of the universal characteristics, i.e. an attribute of human existence. There is no man and society without culture. Another question is whether it is developed or not developed, good or bad, and what the objective criteria for its assessment are [11].

Using categorical approach V. Sagatovsky suggests taking into account the individual forms of culture. He proposes to consider existing approaches to culture as successively located "steps" of its understanding. "Each approach specifies the previous one and makes the necessary contribution to its understanding. All together they turn out to be necessary and sufficient to distinguish culture from other universal phenomena of human being" [11]. Here we mean a few approaches to the definition of culture: ontological, semiotic, activity, value, transcendental. V. Sagatovsky believes that the five approaches to the understanding of culture are successive steps to concretize its understanding. These approaches do not exclude, but mutually complement each other. They lead to the top of the hierarchy, to the foundation that specifies all the basic characteristics.

At the first step, culture appears as the "second nature", a part of the objective reality formed by artifacts. At the second step, it is revealed that these are not just objects of artificial origin, which begin to live according to the new laws of social being, included in its natural historical process. They appear to be processes and results of the activity, subject-object relations, in which the subject can be found in artifacts. At the third step, we see that they are controlled by the world of human meanings, ideal forms, information, which sets the culture specifics. At the fourth step we reveal the value core, which determines the culturally significant direction of all the information. From the second to the fourth step, the process of deepening into subjective reality takes place. And finally, at the fifth step, the particular ontological attitude is determined. Culture is considered in its relation to transcendental reality.

Therefore, the researchers propose a categorical framework (philosophical basis) of the program of subject description and explanation of a particular culture and comparative analysis of different cultures. It is important to start with a statement of specific artifacts and finish with a statement of the nature of the presence or absence of "passionarity", the spirituality of this cultural phenomenon.

\section{RESULTS}

Thus, culture is a semiotic aspect of the process and results of human activity. The subject values and their relationship to the spiritual being are embodied into this activity [11]. From the ontological point of view, culture is a normative activity, symbols, values that reflect all forms of human being. From the "ideological" point of view, culture appears as a quality in relation to the good. This approach is often observed in the media, in everyday speech to highlight the positive values of the society.

Taking culture as a peculiar form of human being and activity, we can offer another basis for the qualification of universals. We consider the proposed "steps" of understanding culture.

On the first step of understanding we speak about culture as the opposite to nature. Culture comprises what is made by a man artificially opposing to natural objects. In fact, these are various artifacts, i.e. artificial objects, material and spiritual, created by a man. Such understanding of culture emphasizes the difference between it and nature, and at the same time, the connection with it - culture grows out of nature. Researchers of this school show the process of separation culture from nature, they classify artifacts as cultural universals and give the grounds for this classification. "Artifacts as anthropogenic objects can be classified on the basis of their functions, which are similar to the physiological functions of various organ systems of the human body (bone and muscular, digestive, respiratory, cardiovascular, excretory, reproductive, immune, and nervous systems). In this way, a person "performs" his functions in the environment, creating a morphological culture substrate in the form of artifacts. This expands his evolutionary possibilities and allows to create a qualitatively new habitat" [13]. In this case, culture is opposed to nature, the artificial, made by man - to natural, biological. Accordingly, universals may differ in terms of their "artificiality", "non-naturalness" as opposed to "natural". This class of universals is the most numerous, that includes all objects created by man - material and ideal, which are also subject to classification. The artifact of culture is the essential universal of culture in this context.

On the second step of understanding we consider culture as an objectified activity. To characterize it, we should use 
universals revealing the process and types activity. Y. Larin calls this a "normative" aspect, which reflects actions, regulations, norms, patterns formed in the process of human activity. V. Stepin pays attention to this feature of culture: "I define culture as a complex, historically developing system of above biological programs of human activity, which stores and broadcasts these programs (a tradition) and also generates new programs of activity, behavior and communication before they are introduced into social life and change it. Culture is the program of activity. People can do it compared with other beings" [2]. This approach helps understand why the societies with similar structures can have different lifestyles. It is due to historical peculiarities of different cultures, e.g. American, Japanese, French, etc. In a well-known work M. Weber shows the influence of Protestant religious orientation on labor in America. Activities and universals expressing it can also be classified for various reasons. Thus, the authors of the monograph "Culture and its types" distinguish twelve types in the morphology of culture [14].

On the third step of understanding we consider culture as meanings and symbols. Formation and development of meanings is a part of culture genesis, which developed along with ontogenesis and phylogenesis. M. Scherbinin shows its development considering the formation of meanings in certain types of art throughout the history of mankind [15]. Culture gives meanings to various objects, both natural and artificial. It is clear that there is no statue as a cultural phenomenon without marble or bronze, i.e. without the material of which it is made. But it is not the material itself that makes the phenomenon of culture, it is an artist's idea that organizes everything, including its aesthetic or spiritual meanings. The external material form acts as a condition for the realization of an idea, the substrate of a cultural phenomenon, a signal of ideal cultural significance. E. Kassirer wrote that "man is an animal, creating symbols," which makes him different from other living beings. Symbols depend on the meaning that is embedded in a particular sign. Meaning formation occurs not only in art, but also in any human activity. Culture is expressed in the meaning; it is a way of its existence. Meanings have different degrees of generalization, functions, and ways of existence. In this respect we speak about universals of culture as objects and concepts (meanings, symbols, denoting objects).

On the fourth step of understanding we consider culture as values. P. Sorokin considered values to be the basis of a culture, he spoke about a change of its three main value systems (ideational, sensitive and idealistic) as its dynamics. This is the most common division of values, although there are other ways of distinguishing them. M. Kagan, for example, believed that a unique spiritual basis in the value (not in the cost) prevails over the pragmatic side of practical reason.

The fifth step of understanding culture is considering it as transcendental. Culture is something spiritual, universal mind, God, a national idea, something beautiful, sublime (according to Plato). Two things that amazed I. Kant were "the starry sky above me" and "the moral law in me." Russian religious philosophers considered this to be Sophia of the God Wisdom.
There is no clear boundary between these aspects, "steps" of culture. Symbols, for example, can act as values, or as transcendental, therefore different universals can be present at all levels of this approach, which is absolutely inevitable. As a rule, one universal dominates in a certain national culture. For example, the values of activity and normativity dominate in the culture of the United States. In the culture of Russia there has always been an aspiration for something transcendental, a search for a national or divine idea.

The authors of the research came to the conclusion that all the universals of culture have common features.

First of all, they reflect the characteristics of all national cultures. In all cultures there are artifacts, values, symbols, spiritual ideals. These characteristics exist in different proportions in different cultures. But their collection is similar. In their concrete historical combination, artifacts, norms, values and symbols form the system of the being and functioning of culture at all stages of its development. As a system-forming principle, one of these forms may be leading in the system of national culture (for example, business, rational culture in the United States, the transcendental in Russian culture).

Secondly, universals have their own peculiarities in each national culture. Different cultures have different values, symbols, and meanings. "Globalization of culture should not lead to its unification, since the "numerator" should always contain specific qualities inherent in a particular local culture .... The emerging global whole can be represented by a multitude of local cultures with the common denominator. This common denominator is the most abstract, common quality, which is present in each local component. Accordingly, this local appears not as an emanation of global integrity, but as the defining of this integrity", argues V. Stepin [2].

Thirdly, universals depend on space-time characteristics. "This is a unity of characteristic to each culture space and time, fixed by the concept of" chronotope", which means literally" time - space "(from the Greek words" chronos "time," topos "- space)." Chronotope "is one of the most common concepts that characterize any culture. Such concepts are called "universals" of culture" [9]. In different historical periods, in different national cultures their content was different.

The fourth point we would like to make is the fact that the system of universals is not closed. In the development of human activity, some universals disappear, others appear, it depends on types of activities, processes of human adaptation to reality. But at the same time, there are also permanent universals expressing the basic human needs. The set of universals in culture shows the degree of social development. In the evolution of universals, both cyclicality and bifurcation are observed. However, the system of universals has orderly nature.

\section{CONCLUSION}

The authors of the research came to the conclusion that all the universals of culture have common features. 
First of all, they reflect the characteristics of all national cultures. In all cultures there are artifacts, values, symbols, spiritual ideals. These characteristics exist in different proportions in different cultures. But their collection is similar. In their concrete historical combination, artifacts, norms, values and symbols form the system of the being and functioning of culture at all stages of its development. As a system-forming principle, one of these forms may be leading in the system of national culture (for example, business, rational culture in the United States, the transcendental in Russian culture).

Secondly, universals have their own peculiarities in each national culture. Different cultures have different values, symbols, and meanings. "Globalization of culture should not lead to its unification, since the "numerator" should always contain specific qualities inherent in a particular local culture. The emerging global whole can be represented by a multitude of local cultures with the common denominator. This common denominator is the most abstract, common quality, which is present in each local component. Accordingly, this local appears not as an emanation of global integrity, but as the defining of this integrity", argues V. Stepin [2].

Thirdly, universals depend on space-time characteristics. "This is a unity of characteristic to each culture space and time, fixed by the concept of" chronotope", which means literally" time - space "(from the Greek words" chronos "time," topos "- space)." Chronotope "is one of the most common concepts that characterize any culture. Such concepts are called "universals" of culture" [16]. In different historical periods, in different national cultures their content was different.

The fourth point we would like to make is the fact that the system of universals is not closed. In the development of human activity, some universals disappear, others appear, it depends on types of activities, processes of human adaptation to reality. But at the same time, there are also permanent universals expressing the basic human needs. The set of universals in culture shows the degree of social development. In the evolution of universals, both cyclicality and bifurcation are observed. However, the system of universals has orderly nature.

\section{References}

[1] T. Oizerman, Are there universals in the sphere of culture. "Questions of Philosophy", p. 292, 1989

[2] V. S. Stepin, Civilization and culture. SPB: SPBGUP, 2011, p. 408

[3] N. Smelzer, Sociology, M, Phoenix, 1994, p. 688

[4] J. J. Clarke, "On the unity and diversity of cultures", American Anthropologist, 72, 1970, pp. 545-554.

[5] T. Parsons, "The concept of society: the components and their relationships", American sociological thought, 1996, pp. 494-526.

[6] A. I. Kravchenko, Culturology, M., 2000, pp. 16-19.

[7] M. A. Mozheiko, Universals. Postmodernism. Encyclopedia, Minsk, Book House, 2001, p. 1040

[8] K. G. Isupov, Universals of civilization, Slovari - Onlain.ru.

[9] M. I. Naidorf, Introduction to the theory of culture. Basic concepts of cultural studies, Odessa, Druk, 2005, p. 168

[10] Y. V. Larin, Onto-logic of culture. Monograph, Tyumen, Tyumen State University, 2004, p. 164

[11] V. N. Sagatovsky, "Interchangeability of basic approaches to understanding culture. Attempt to synthesis", Fundamental problems of cultural science, Vol. 4, 2008, pp. 151-161.

[12] F. A. Selivanov, Good, truth, connection, Tyumen, RIC TGAKI, 2006, p. 260

[13] E. Belov, Artifact as a structural unit of culture, Tyumen, 2013, p. 230

[14] K. G. Rozhko, Culture and its types, Tyumen, Vector Book, 2002, p. 192

[15] M. N. Scherbinin, Art and philosophy in the genesis of sense formation (Experience of aesthetic anthropology), Tyumen, Tyumen State University, 2005, p. 312

[16] L. N. Zakharova, Continuum culture of the regions. Collective monograph, Tyumen, 2012, pp. 135-157. 